\title{
Simplified anastomotic technique for end-to-side bronchial reimplantation onto the trachea or contralateral main bronchus after complex tracheobronchial resections
}

\author{
Gaetano Di Rienzo, MD, Tetsuhiko Go, MD, and Paolo Macchiarini, MD, PhD, Hannover, Germany
}

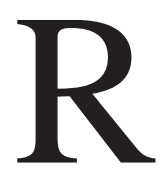

ecent anesthetic and surgical advances have remarkably reduced the frequency of airway complications after tracheobronchial resections, yet the end-to-side reimplantation of a main, lobar, or intermedius bronchus onto the trachea or the side of the contralateral main bronchus still represents a major technical challenge with high anastomotic morbidity and procedure-related mortality. ${ }^{1}$ We present the results of a simplified anastomotic technique for end-to-side reimplantation of the lobar or intermedius bronchus onto the trachea or contralateral main bronchus after extensive bronchial sleeve resections or carinal lobectomy.

\section{Clinical Summary}

Since April 1999, 10 patients underwent an elective tracheobronchial resection with 6 different types of end-to-side secondary anastomoses for benign (Table 1) or malignant (Table 2) processes. All patients received total intravenous anesthesia with a process electroencephalogram and were intubated through a double-lumen endobronchial tube, and the intraoperative intermittent cross-field ventilation concept was used. ${ }^{2}$ Right-sided tumors were approached through an ipsilateral muscle-sparing posterolateral thoracotomy in the fifth intercostal space, and left-sided tumors were managed with a midline transsternal approach. All patients with cancer had a complete nodal dissection. The basic surgical principles of carinal resection and end-to-end primary anastomosis outlined by Grillo ${ }^{3}$ and us ${ }^{2,4}$ were followed.

There are, however, peculiarities of the bronchial end-to-side secondary reimplantation. First, the opening on the receiving trachea or bronchus should be large enough (at least 1 to $1.5 \mathrm{~cm}^{2}$ ) to host the implanting bronchus and within the first $1 \mathrm{~cm}$ from the end-to-end anastomosis to avoid intervening airway necrosis. Depending on the type of reimplantation, the opening should be created either entirely on the cartilage wall for intermedius bronchus reimplantations or include the edge between the cartilage and membranous wall for reimplantation of the superficial (membra-

From the Department of Thoracic and Vascular Surgery, Heidehaus Hospital (Hannover Medical School), Hannover, Germany.

Received for publication Jan 4, 2002; accepted for publication Feb 14, 2002.

Address for reprints: Paolo Macchiarini, MD, PhD, Department of Thoracic and Vascular Surgery, Heidehaus Hospital (Hannover Medical School), Am Leineufer 70, 30419 Hannover, Germany (E-mail: pmacchiarini@ compuserve.com)

J Thorac Cardiovasc Surg 2002;124:632-5

Copyright $(9) 2002$ by The American Association for Thoracic Surgery

$0022-5223 / 2002 \$ 35.00+0 \quad \mathbf{1 2 / 5 4 / 1 2 4 5 0 1}$

doi: $10.1067 / \mathrm{mtc} .2002 .124501$ nous) aspect of a lobar bronchus. The reimplanting lobar bronchus should be sectioned beyond its takeoff to include less than $0.5 \mathrm{~cm}$ before its segmental trifurcation to avoid kinking, excessive tension on the reimplanting membranous wall, and ischemia.

Second, the end-to-side anastomosis is then started by using the parachute principle (Figure 1). A double-ended polydioxanone (PDS; Ethicon Inc, Sommerville, NJ) 3-0 or 4-0 suture is inserted from within the lumen to complete the deepest and entire aspect of the anastomosis and is left untied (Figure 2, A). Once the placement is completed, the double-ended suture is pulled tight as the reimplanting and recipient lumens are approximated; care must be paid to avoid a purse-string effect. We recommend turning the airway mucosa inward and regularly approximating the parachuting sutures (Figure 2, B) through nerves hooks. While the doubleended PDS suture is kept on traction, it is gently fixed with 2 separate PDS sutures of the same size beyond both edges. Several concentric interrupted 3-0 to 5-0 polyglactin (Vicryl, Ethicon Inc) sutures are then placed on the remaining quadrants 3 to $4 \mathrm{~mm}$ apart and 3 to $4 \mathrm{~mm}$ from the cut edge of the airway, leaving the membranous wall of the reimplanting bronchus until last to allow balancing of any anastomotic disparity and excessive traction on it. We found that placing small Vicryl sutures (eg, 5-0) on the membranous wall reduces the manipulation risks of injury (Figure 3 ). Once placement is completed, the walls and sutures are gently approximated, and the knots are tied outside the airway. The anastomosis is then tested for air leaks to $40 \mathrm{~mm} \mathrm{Hg}$ and repaired if needed. A circumferential anastomotic wrap with viable tissue is optional, but release maneuvers are mandatory.

All patients were extubated in the operating theater. With the exception of one postoperative atrial fibrillation, no major complications were recorded. All patients with lung cancer had an R0 resection. The median postoperative hospital stay was 13 days. All patients are alive and without evidence of tumor recurrence, functional or anatomic anastomotic early or late complications, or both at a 21-month median follow-up (range, 5-26 months), as assessed by means of postoperative routine clinical and endoscopic surveillance.

\section{Discussion}

The advantages of the parachute technique presented here are that it permits a less traumatic handling of the bronchial walls and direct anastomotic visualization and is quicker and easier to perform than the interrupted technique suture, thereby reducing the significant technical challenges traditionally reported with the endto-side secondary anastomosis. ${ }^{1}$ However, beyond those details outlined above, several other technical details are as important as the execution of the parachute technique in determining the outcome, namely the creation of a sufficiently large square orifice on the hosting surface to widely host the reimplanting bronchus, avoidance of the oblique trimming of the reimplanting bronchial 
TABLE 1. Profile of patients with benign lesions undergoing sleeve main stem and intermedius bronchi resection and tracheal reimplantation of the right upper lobe bronchus

\begin{tabular}{|c|c|c|c|c|c|}
\hline $\begin{array}{l}\text { Patient } \\
\text { no. }\end{array}$ & Sex & Age (y) & Type of lesion & Involved bronchial system & Type of operation \\
\hline 1 & $\mathrm{~F}$ & 31 & $\begin{array}{l}\text { latrogenic perforation } \\
\text { of RMSB and } \mathrm{BI}\end{array}$ & Origin of RMSB and IB & $\begin{array}{l}\text { Sleeve RMSB and IB resection } \\
\text { and anastomosis between } \\
\text { middle-lower lobe carina } \\
\text { and origin RMSB plus } \\
\text { reimplantation RULB onto } \\
\text { ventral TR }\end{array}$ \\
\hline 2 & $\mathrm{~F}$ & 26 & $\begin{array}{l}\text { Inflammatory } \\
\text { pseudotumor of } \\
\text { RMSB and } \mathrm{BI}\end{array}$ & $\begin{array}{l}\text { Membranous wall of } \\
\text { RMSB and distal IB }\end{array}$ & $\begin{array}{l}\text { Sleeve RMSB and IB resection } \\
\text { and anastomosis between } \\
\text { distal IB and origin RMSB } \\
\text { plus reimplantation RULB } \\
\text { onto ventral TR }\end{array}$ \\
\hline 3 & $\mathrm{~F}$ & 51 & $\begin{array}{l}\text { Post-DLT anastomotic } \\
\text { stenosis of distal } \\
\text { RMSB and proximal BI }\end{array}$ & $\begin{array}{l}\text { Entire donor's RMSB and } \\
\text { proximal IB }\end{array}$ & $\begin{array}{l}\text { Sleeve RMSB and IB resection } \\
\text { and anastomosis between } \\
\text { middle-lower lobe carina } \\
\text { and origin RMSB plus } \\
\text { reimplantation RULB onto } \\
\text { ventral TR }\end{array}$ \\
\hline
\end{tabular}

$R M S B$, right main stem bronchus; $B I$, bronchus intermedius; $R U L B$, right upper lobe bronchus; $D L T$, double-lung transplantation; $T R$, trachea.

TABLE 2. Tracheobronchial reconstructions for non-small cell lung cancer

\begin{tabular}{|c|c|c|c|c|c|c|}
\hline $\begin{array}{l}\text { Patient } \\
\text { no. }\end{array}$ & Sex & Age (y) & Type of tumor & Site & Type of operation & pTNM \\
\hline 1 & $\mathrm{M}$ & 69 & Squamous & RUL and ML & $\begin{array}{l}\text { Carinal right upper bilobectomy; } \\
\text { anastomosis between TR and } \\
\text { LMSB; reimplantation BI onto } \\
\text { TR }\end{array}$ & T4 N1 \\
\hline 2 & $\mathrm{M}$ & 64 & Squamous & RULB + RMSB + chest wall & $\begin{array}{l}\text { Carinal right upper lobectomy; } \\
\text { anastomosis TR-LMSB; } \\
\text { reimplantation BI-LMSB }\end{array}$ & T4 N1 \\
\hline 3 & $\mathrm{M}$ & 65 & Relapsing bronchoalveolar* & $\begin{array}{l}\text { RUL bronchus stump plus } \\
\text { proximal RMSB }\end{array}$ & $\begin{array}{l}\text { Carinal resection plus sleeve } \\
\text { main bronchial and RUL } \\
\text { stump resection; anastomosis } \\
\text { TR-LMSB; reimplantation BI- } \\
\text { TR }\end{array}$ & T4 NO \\
\hline 4 & $\mathrm{M}$ & 70 & Squamous & RLL tumor & $\begin{array}{l}\text { Carinal right lower bilobectomy; } \\
\text { anastomosis TR-LMSB; } \\
\text { reimplantation RUL-TR }\end{array}$ & T4 NO \\
\hline 5 & $\mathrm{M}$ & 71 & Squamous & LLL & $\begin{array}{l}\text { Left lower lobectomy and } \\
\text { carinal resection; } \\
\text { anastomosis TR-RMSB; } \\
\text { reimplantation LSMB-RMSB }\end{array}$ & T4 NO \\
\hline 6 & $\mathrm{M}$ & 45 & Squamous & RLL & $\begin{array}{l}\text { Carinal right lower bilobectomy; } \\
\text { anastomosis TR-LMSB; } \\
\text { reimplantation RUL-TR }\end{array}$ & T4 NO \\
\hline 7 & $\mathrm{M}$ & 76 & Adenocarcinoma & RUL & $\begin{array}{l}\text { Carinal right upper lobectomy; } \\
\text { anastomosis TR-LMSB; } \\
\text { reimplantation BI-LMSB }\end{array}$ & T4 N0 \\
\hline
\end{tabular}

Patient 2 had an associated en bloc chest wall resection (first to fourth ribs). All patients had an ASA score of 3. RUL, Right upper lobe; $M L$, middle lobe; $T R$, trachea; $L M S B$, left main stem bronchus; $B I$, bronchus intermedius; $R U L B$, right upper lobe bronchus; $R M S B$, right main stem bronchus; $R L L$, right lower lobe; $L L L$, left lower lobe.

${ }^{*}$ After right upper lobectomy 8 months previously. 


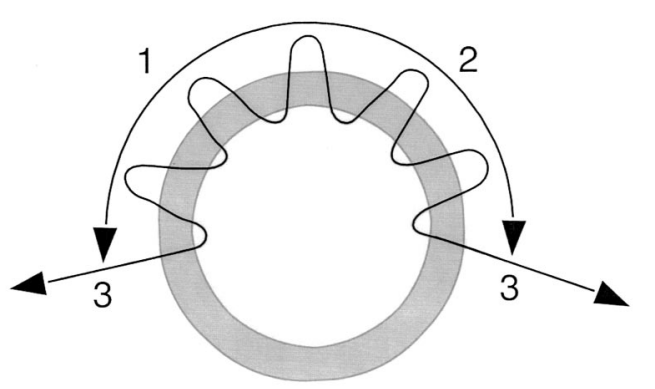

Figure 1. Drawing depicting the parachute principle. The starting point (3) of the double-ended polydioxanone (PDS) suture should be offset to one edge or the other of the deepest or posterior part of the anastomosis, depending on the local geometry. This permits a better visualization and quicker and simplified performance of the anastomosis. The ventral part is then completed with interrupted sutures.

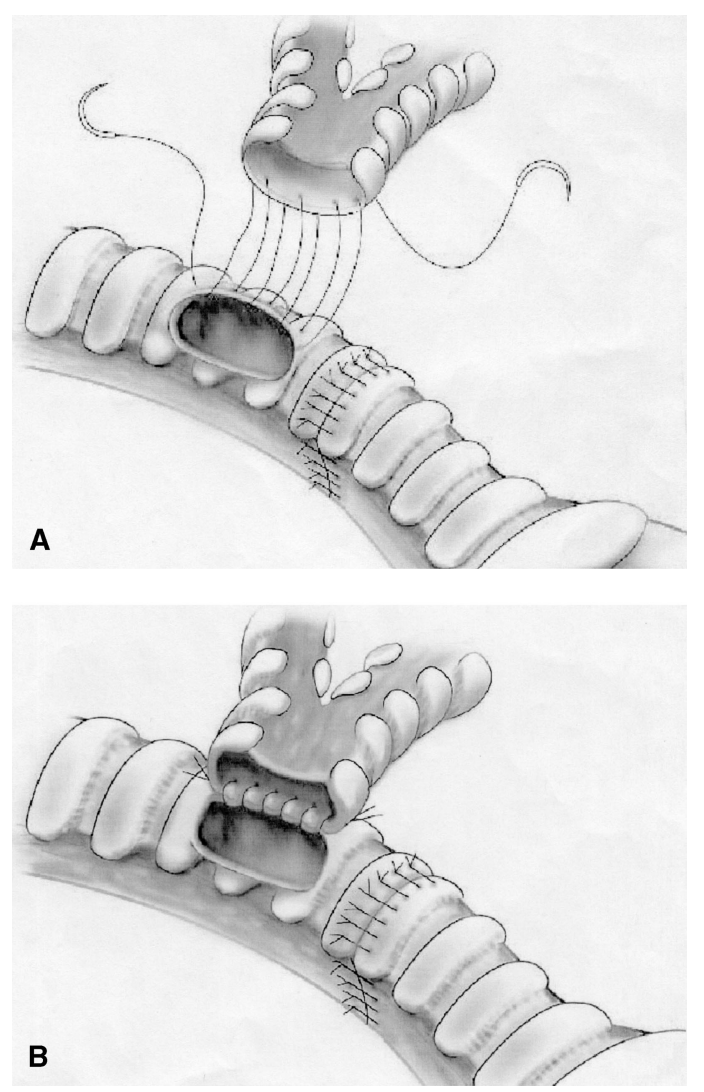

Figure 2. A, A double-ended PDS 3-0 or 4-0 suture is started on one or the other edges of the deepest or posterior aspect of the anastomosis, picking up the full layers of the respective bronchial walls, and inserting the needles from inside the lumen. It must be left untied to allow a number of stitches to be placed to complete the entire deepest aspect of the anastomosis before the reimplanting bronchus is pulled down onto the hosting structure. $B$, The double-ended suture is then pulled tight as the reimplanting and recipient lumens are parachuted. We recommend using the exact mucosa and stitch apposition through nerve hooks to avoid purse-string and narrows effects.

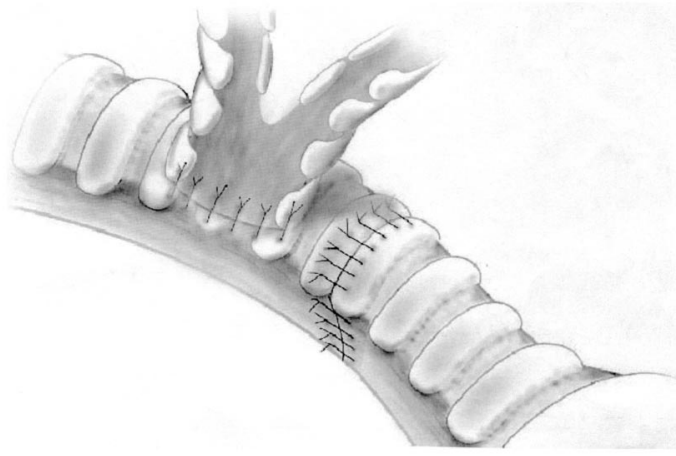

Figure 3. Several concentric interrupted 3-0 to 5-0 polyglactin (Vicryl) sutures are placed on the remaining quadrants 3 to $4 \mathrm{~mm}$ apart and 3 to $4 \mathrm{~mm}$ from the cut edge of the airway, leaving the membranous wall of the reimplanting bronchus until last to allow balancing of any anastomotic disparity and excessive traction on it. We found that placing small Vicryl sutures $(e g, 5-0)$ on the membranous wall reduces the manipulation risks of injury. Once placement is completed, the wall and sutures are gently approximated, placing knots outside walls.

takeoff to prevent its kinking and narrowing, and placement of the stump of the right upper lobar bronchus to be reimplanted into the trachea within $0.5 \mathrm{~cm}$ before its segmental trifurcation, especially in patients with non-small cell lung cancer, in which the systemic nodal dissection inevitably leads to division of the bronchial blood supply.

With carinal lobectomy, it has been suggested that advancement of the bronchus intermedius to the level of the trachea can lead to airway necrosis and narrowing caused by anastomotic angulation, devascularization, and tension, and thus reimplantation of intermedius bronchus into the left main bronchus appears to be safer. ${ }^{1}$ We believe, however, that through an extended pericardial, mediastinal, and tracheal mobilization, a safe tracheal reimplantation is almost feasible when a tension-free anastomosis can be avoided and some surrounding tissue providing some degree of systemic blood supply to the anastomosis is preserved. On the other hand, performing the end-to-side secondary anastomosis on the left main bronchus, although feasible, is almost more technically demanding because the anastomosis must be made between the esophagus dorsally and the pericardium ventrally, especially during the apnea intervals, where the region lies very deep in the mediastinum. However, even in these cases the impaired visualization and handling can be better managed with a modification of the parachute technique by placing a series of running stitches at what will become the heel of the anastomosis, with the reimplanting and hosting bronchi separated, and then pulling tight as the bronchi are approximated.

\section{Conclusion}

The described parachute technique significantly simplifies the technical challenges and reduces the potential for postoperative anastomotic complications of the end-to-side secondary reimplantation of a lobar or intermedius bronchus into the trachea or contralateral main bronchus. 


\section{References}

1. Michell JD, Mathisen DJ, Wright CD, Wain JC, Donahue DM, Moncure AC, et al. Clinical experience with carinal resection. J Thorac Cardiovasc Surg. 1999;117:39-53.

2. Dartevelle P, Macchiarini P. Carinal pneumonectomy for bronchogenic carcinoma. Semin Thorac Cardiovasc Surg. 1996;8:414-25.
3. Grillo HC. Carinal reconstruction. Ann Thorac Surg. 1982;34:35673.

4. Schröder C, Vogel B, Krause J, Macchiarini P. Tracheal reimplantation of the right upper lobe bronchus with sleeve main and intermedius bronchus resection and reconstruction. $J$ Thorac Cardiovasc Surg. 2001;121:388-90. 